\title{
ARTILLERÍA Y POLIORCÉTICA CASTELLANA EN LA ESTRATEGIA DE FERNANDO EL CATÓLICO CONTRA FRANCIA. (DOCUMENTOS PARA SU ESTUDIO)
}

\author{
POR \\ FERNANDO COBOS GUERRA y JOSÉ JAVIER DE CASTRO FERNÁNDEZ
}

\section{RESUMEN - RÉSUMÉ}

Se presenta un conjunto de documentos inéditos (1475-1503) sobre las dotaciones, características y empleo de la artillería, tanto española como francesa, en el asalto y defensa de las fortalezas, vinculándose la estrategia de su desarrollo al de las fortalezas claves del periodo de transición. Se apunta así una estrategia específica y distinta del resto de Europa en la España de los Reyes Católicos bajo cuyo reinado los responsables de la artillería y de la fortificación eran un mismo cuerpo de artilleros que desarrollaron sofisticados sistemas tanto de asalto como de defensa.

Nous présentons un ensemble de documents inédits (1475-1503) concernant l'équipement, les caractéristiques et l'usage de l'artillerie, aussi bien espagnole que française, dans l'assaut et la défense des fortereses, en établissant clés un lien entre la stratégie de leur développement et celui propre des forteresses clés de la période de transition. Nous esquissons, ainsi, une stratégie spécifique el différente su reste de 1’Europe, celle de l’Espagne des Rois Catholiques oú les responsables de l'artillerie et de la fortification étaient un seul corps d'artilleurs qui développaient des systémes sophistiqués, soit d'assaut, soit de défense des places.

\section{PALABRAS CLAVE - MOTS CLÉS}

Fortificación de transición. Trenes de artillería. Minas y contraminas. Fundiciones de bronce.

Fortification de Transition. Trains d'artilleries. Mines. Contre-mines. Fonderie en bronze.

El ímpetu y poderío de la artillería francesa en las campañas de Carlos VIII en Italia y la destrucción, casi absoluta, que sufrió la fortaleza vieja de Salsas en 1496 ante el arrollador fuego del tren de artillería francés han hecho pensar en la imprevisión y desconocimiento del enemigo que tenía Fernando el Católico en los primeros enfrentamientos hispano-franceses por el dominio de Italia. Sin embargo cuando en 1503 las tropas francesas salen derrotadas, tanto en Nápoles como en el Rosellón, la paradójica ausencia de piezas de gran calibre en el ejército castellano evidencia una estrategia premeditada de fundición de piezas y de adaptación de los diseños defensivos y de las técnicas de asalto, y especialmente las minas, que serán claves en el desenlace de la guerra.

Pretendemos aquí apuntar con alguna documentación inédita el desarrollo de esta estrategia, demostrando como Fernando el Católico estaba perfectamente informado del potencial enemigo y sin embargo optó, él o sus capitanes de artillería, por una estrategia aparentemente contradictoria. No conviene en todo caso olvidar que tanto la fundición de piezas como la construcción de fortalezas dependía de la capitanía general de la artillería y los artilleros, específicamente en este caso el comendador Ramiro López o el capitán Pedro Navarro, igual 
fundían cañones, dirigían baterías o construían minas, que diseñaban fortalezas capaces de resistir asaltos de artillería o ataques con minas. No existe por tanto, a diferencia de buena parte de los ingenieros italianos del siglo XVI, distinción alguna entre los diseñadores de fortalezas y los encargados de tomarlas.

Puede decirse que hasta la guerra de Sucesión de Enrique IV el parque estable de artillería castellana era prácticamente inexistente, por mucho que algunas fortalezas, como el alcázar de Segovia, hubieran estado fuertemente $\operatorname{artilladas}^{1}$, y la artillería se agrupaba o se compraba para campañas concretas. La carencia de piezas propias se solucionó en la toma de Zamora, en poder de los portugueses en 1475, con el préstamo de cinco lombardas grandes y medianas y dos ingenios (trabucos, posiblemente) que hizo el duque de Alba a las tropas de Fernando el Católico y cuya valoración refleja el documento 1 que se anexa al final de este artículo. Destaca en el citado texto el alto precio en el que se tasa el tren de artillería (480.000 maravedís), casi la mitad del coste de una fortaleza pequeña. Entonces se evidenció también que en Castilla no existían tampoco fortalezas adecuadas para resistir el ataque de trenes de artillería. La respuesta castellana a la experiencia de esta guerra fue la construcción de la barrera artillera entorno al castillo de la Mota en Medina del Campo, dispuesto con cuatro niveles de tiro de los que dos quedan ocultos en el foso, por debajo de la cota del campo exterior. La construcción de la barrera de la Mota, con su baluarte avanzado que protegía la puerta, se comenzó en 1476 y se acabó en 1483 y ya evidencia una decisión estratégica que será clave en el éxito de la defensa de Salsas en 1503. No es este el lugar para extenderse en las innovadoras características de esta paradigmática fortaleza de transición ${ }^{2}$, pero por la sección que acompañamos puede verse que la barrera estaba concebida para poderse defender desde las dos líneas ocultas en el foso cuando la artillería asaltante hubiera desmontado las piezas de las azoteas y de las cámaras que baten con fuego rasante la campaña. Presenta además un pozo avanzado con funciones de contramina que luego caracterizará a todas las fortalezas de transición castellanas ${ }^{3}$, indicación evidente de que la mina y específicamente la más dañina mina explosiva podía estar ya siendo considerada como una técnica eficaz de asalto y por tanto potencialmente peligrosa para la nueva fortaleza ${ }^{4}$.

Lo más singular, en todo caso, de la barrera de la Mota es la proliferación de bocas de tiro, casi doscientas, de las cuales la mayor parte de ellas corresponden a calibres muy pequeños, ribadoquines o medio ribadoquines, con no pocas aberturas adicionales para espingardas y armas de mano. Se optaba así por basar la defensa de la fortaleza, y específicamente de los fosos con armas de fuego de muy pequeño calibre, renunciando a emplazar piezas de gran calibre o plantear defensas de cañón contra cañón. Esta estrategia será común a todas las

SigLAS UTILIZADAS:

ADA. Archivo del Ducado de Alba.

AGS. Archivo General de Simancas.

AHN. Archivo Histórico Nacional.

ANT. Archivo de la Nobleza de Toledo.

RAH. Real Academia de la Historia.

1 COBOS y DE CASTRO,1998a: 132.

2 Cobos y De CASTRO, 1998b. Cobos y De CASTro, 2000b.

3 COBOS, 2000

4 La Mota inicia el desarrollo de complejos sistemas contramina que parecen responder a una preocupación creciente por el peligro de esta técnica, especialmente indicada para fortalezas que pueden defenderse con éxito de las baterías de artillería. Las minas, aunque no explosivas se emplearon prolijamente en el asalto al castillo de Burgos en 1475 y en 1487 el capitán general de la artillería, Francisco Ramírez de Madrid, había empleado con éxito una mina explosiva contra una torre de las defensas de Málaga. La previsión de defensas contramina puede indicar tanto un desarrollo inicial de la mina explosiva como la convicción por parte de los diseñadores de que su fortaleza oculta en el foso y con abundantes defensas en estos niveles no podría ser tomada por otro sistema. De hecho, en casi todos los asaltos de fortalezas de transición bien protegidas contra la artillería (Salsas y Nápoles 1503 o Rodas 1522) las minas fueron determinantes. 
teorías defensivas españolas del siglo XVI donde se potencian las defensas cubiertas y escondidas de los fosos y se basa la defensa de las plazas antes en los arcabuces que en los cañones ${ }^{5}$. Tal despliegue de bocas de fuego no era en ningún caso un ejercicio retórico, como pudo ocurrir en muchas fortalezas señoriales, detrás de cuyas troneras nunca hubo pieza alguna; de la Mota sabemos que en 1501 tenía 120 piezas montadas ${ }^{6}$.

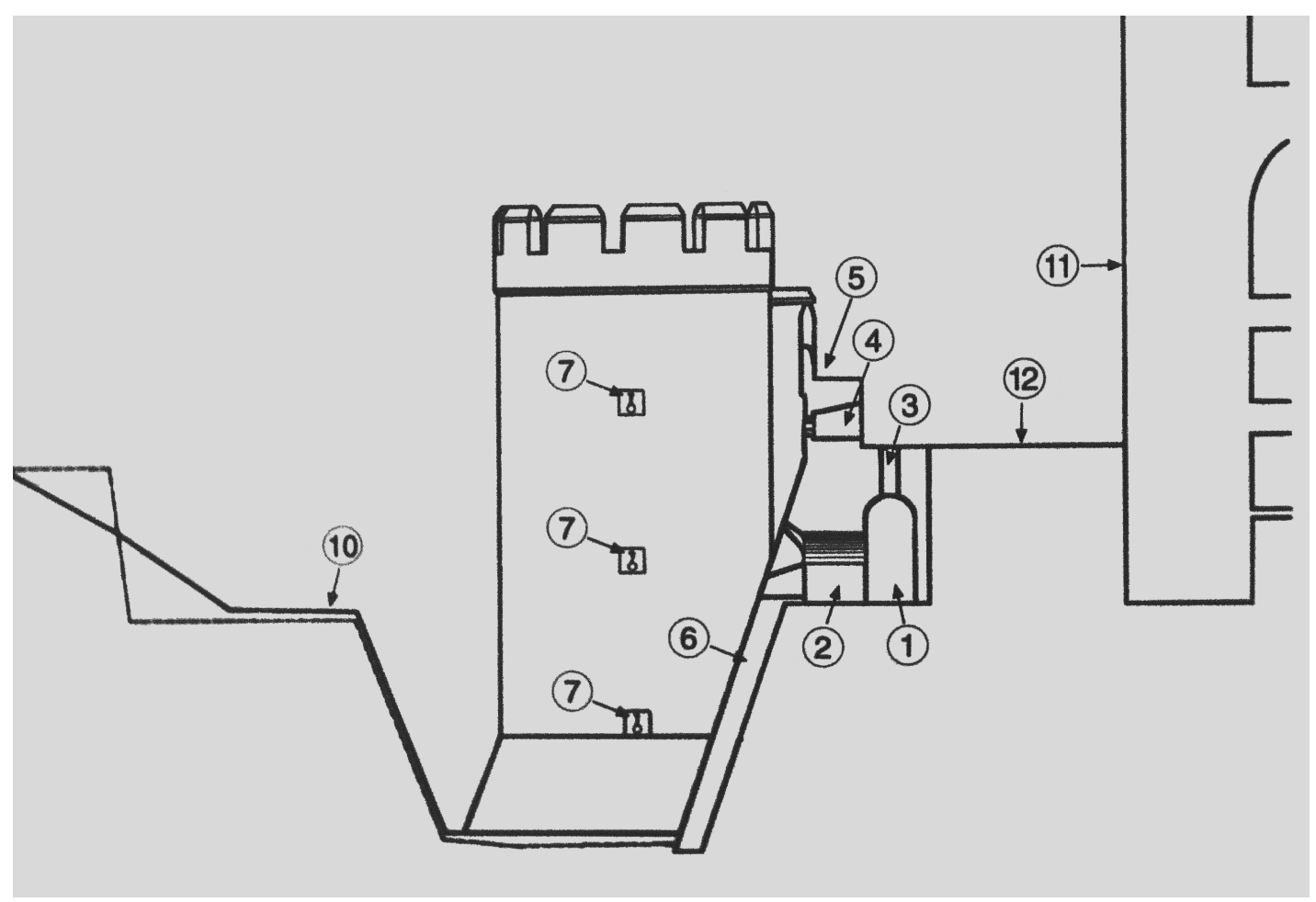

Fig. 1. Sección de la barrera del castillo de la Mota (1476-1483).

Salvo unas pocas piezas que provienen del alcázar de Segovia ${ }^{7}$, nada sabemos de la procedencia de las piezas que guarnecían la Mota en los primeros años después de su construcción antes de la instalación de la fundición de artillería que se encomienda al artillero Ramiro López en Medina, a la sombra de este castillo. Poco sabemos en todo caso del tipo de piezas que pudieron fundirse en un primer momento. Sin embargo, cuando en 1486 se subleva el conde de Lemos y Ramiro López debe dirigir el tren de artillería para la toma del castillo de Ponferrada, la artillería que el maestro Ramiro saca del parque de Medina debe completarse con aportes de piezas gruesas de diversos nobles. La escasez de piezas gruesas de la Corona, empeñada en esos momentos en la guerra de Granada, contrasta con la facilidad para proveerse de piezas de pequeño calibre y el propio Ramiro es capaz de fundir sobre la marcha 17 ribadoquines de bronce que se emplean en el asalto y de los que 3 quedan en Ponferrada y

${ }^{5}$ Escrivá defendía en su Apología de 1538 esta teoría «porque no se deve constreñir ni limitar la fortification a que solamente pieças gruessas la puedan defender» y criticaba a los que proponían defenderse desde lo alto de las fortalezas «cañón contra cañón». COBOS y DE CASTRO, 2000a:110 y 133.

6 CAAMAÑO, 1959: 184.

7 COBOS y DE CASTRO, 1998a:229. 
3 se llevan a Galicia, entregándose el resto al parque de artillería de Medina del Campo. Las pormenorizadas cuentas de la toma de Ponferrada ${ }^{8}$ incluyen interesantes datos sobre la fundición y otros utillajes de la artillería que hemos extractado en el documento 2 que se anexa.

Esta no es desde luego la tónica general de los ejércitos potencialmente enemigos de Fernando el Católico y la respuesta portuguesa al todavía latente conflicto con Castilla, podría haber consistido significativamente en la forja de lombardas de extraordinario tamaño que se emplazaron en algunas fortalezas. Significativo es el caso de la «bombarda» de 33,5 cms. de calibre que se conserva en la fortaleza fronteriza de Pinhel y que puede identificarse con una de las dos «tercenas» que mandó emplazar de nuevo Juan II de Portugal en $1488^{9}$ cuando aún «as coisas com Castela nao eram de fiar ${ }^{10}$. Aproximadamente de este mismo año, 1488, es el detallado informe que envía un espía de Fernando el Católico (documento 3) sobre el tren de artillería que ha concentrado el rey de Francia en Tours con motivo de la anexión del condado de Bretaña. La relación que envía el espía al monarca español representa una de las más detalladas informaciones que se conocen de la artillería del siglo XV y especifica pormenorizadamente el tamaño de las piezas, su peso, su material (todos de fuslera), el alcance de su tiro, la penetración del bolaño sobre un muro e incluso las características de las carretas que las transportan. Destaca el potencial del tren de artillería francés que incluye 16 lombardas que disparan pelotas de hierro de dos palmos (aprox. $42 \mathrm{cms}$ ) de calibre, 24 cañones para pelotas de hierro de un palmo, 12 cañones para pelotas de piedra, 4 serpentinas para pelotas de hierro de un palmo, y 41 culebrinas para pelotas de plomo. Por tan interesante informe conocemos, y conoció Fernando el Católico, que todas las piezas eran de fundición, fuslera, con las matizaciones que hacemos al final de este artículo; que la mayor parte de la munición era de hierro o plomo fundido, y que muchas piezas eran capaces de disparar directamente desde los carros que las transportaban.

De todo este despliegue tecnológico francés el dato más sorprendente es el increible alcance (dos leguas de Francia) y poder de penetración (hasta más de $8 \mathrm{mts}$.) que el informe adjudicaba a las piezas francesas cuando disparaban sobre «muro o fuertes baluartes» y aunque este dato es con seguridad exagerado, Fernando el Católico debía saber que ninguna de sus fortalezas, salvo quizá la Mota, hubiera podido resistir un asalto de este tren de artillería. Es posiblemente la convicción de la imposibilidad de defenderse ante este peligro con fortalezas que buscaran un enfrentamiento directo de cañón contra cañón, la que va a guiar las decisiones de los años siguientes, incidiendo en la fundición de piezas ligeras y en la construcción de fortalezas escondidas por profundos fosos del fuego enemigo. La renuncia por tanto a fundir cañones de gran calibre implicaba sin embargo una desventaja clara a la hora de asaltar fortalezas, desventaja que tras el éxito de la mina explosiva en Málaga en 1487 podría compensarse, y de hecho se compensó, con el empleo de esta técnica. Todos los datos que conocemos de mediados de la década de los 90 avalan esta hipótesis.

Así, el inventario de la artillería que había en Granada hacia $1495^{11}$ indica que aparte de las 20 serpentinas de hierro la base fundamental del parque eran 20 ribadoquines y 20 sacabuches, y en ese mismo año los RRCC ordenaban fundir 200 piezas de bronce entre las que había 12 pasavolantes de 17 quintales, 18 pasavolantes del tipo san Cristóbal de 12 quintales, 65 ribadoquines del tipo San Miguel de 4 quintales, 25 cervatanas de 6 quintales con recámara y 80 ribadoquines pequeños de 2 o 3 quintales ${ }^{12}$. Eran todas ellas piezas pequeñas - los pasavolantes más grandes no llegarían a los $20 \mathrm{~cm}$ de calibre- y los inventarios que se hacen sobre la artillería disponible en esos mismos años, aunque reflejan la existencia de

\footnotetext{
8 Que reproducimos detalladamente en: COBOS y DE CASTRO, 2000c.

9 «Novamente fazer a Taracena da Villa de Pinhel». PORTO, 1982:102.

10 SILVA, 1996: 104.

11 CoBos, 1994: 325.

12 AGS. Libro II Cámara. Sept. 1495. Transcrito por ARÁNTEGUI, 1887: 305-6.
} 
algunas lombardas de fuslera o de metal que reciben el significativo nombre de «lombardas del Rey» y algunas otras piezas de hierro de grueso calibre, recogen ya entonces muchas más piezas de pequeño calibre ${ }^{13}$.

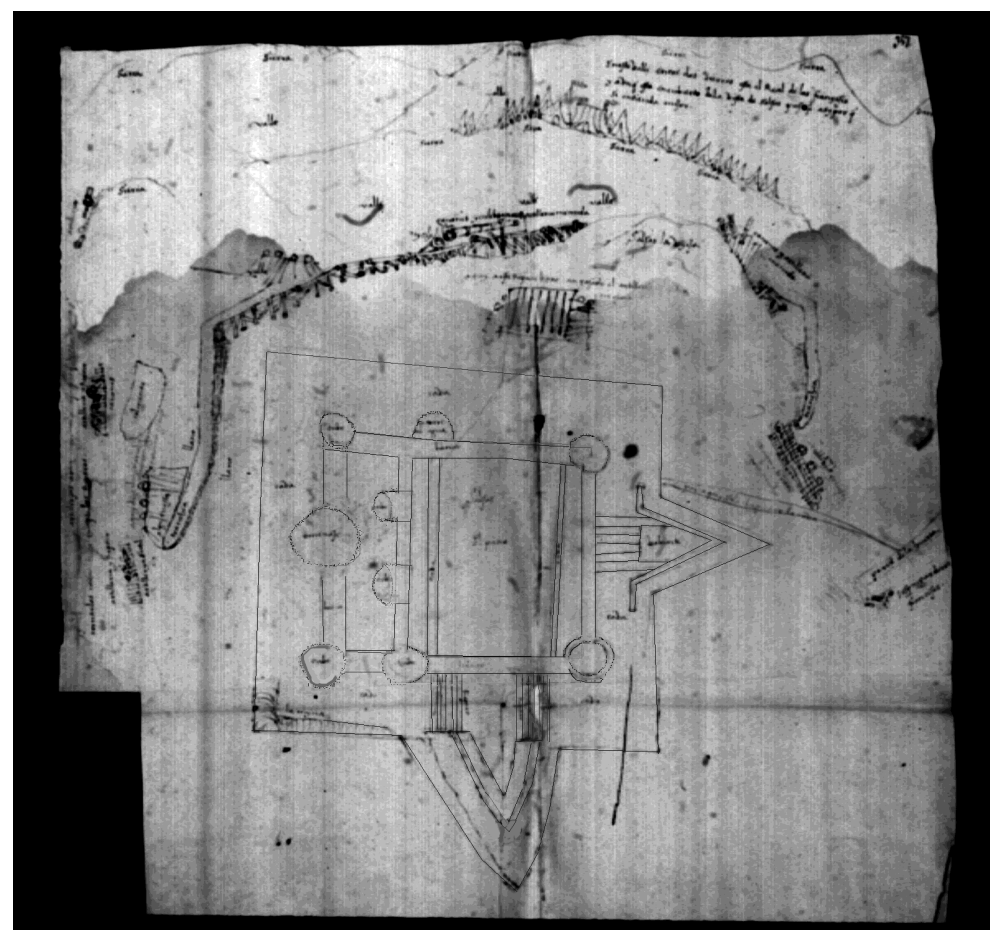

Fig. 2. Plano de Gonzalo de Ayora del sitio de Salsas (1503). RAH. CSC. A-11, fol 357, con las trazas del fuerte repasadas para facilitar su lectura (transcrito íntegramente en CoBOS y De CASTRO,1998b: 23.)

Por otro lado, hacia 1496, debía estar suficientemente avanzada la obra del castillo de Coca, donde aparece un sofisticado sistema contramina ${ }^{14}$ cuyo pozo de escucha presenta un nivel freático artificialmente alimentado. De esa misma época es la orden dada al artillero mayor Ramiro López para que «llegado a Salsas aveys de mirar mucho si se puede fortalecer aquella villa para que quede bien fuerte y si tal disposicion toviere para que se pueda fortalecer aveys de ver que tiempo y con que costa y con que gente y con que recabdo se podra fortalecer para quedar de todo punto acabada si tal disposicion no tubiere que obra se podra haser para sufrir cualquier gente por treinta o cuarenta dias fasta ser socorrida ${ }^{15}$. Y es en Salsas, en la fortaleza nueva construida por Ramiro López a partir de 1497, donde se aúnan los sistemas defensivos ya construidos antes en Castilla, con las galerías inferiores que cubren el foso que aparecían en la Mota, en un diseño que pretendía también esconderse del fuego enemigo y defenderse en los fosos, y con las obras avanzadas, que los castellanos lla-

13 ARÁNTEGUI, 1887: 311-317.

14 Cobos y De CASTRO, 1998a: 236-237.

15 Carta de Fernando el Católico a Ramiro López dada en Alfaro el 31 de octubre de 1495. AGS. Libro II de Cámara, año 1495. Transcrito por ARÁNTEGUI, 1887: 318-320. 
maban baluartes. Salsas incorporaba también, como veremos, un sistema contramina general para todo el foso basado en un nivel freático artificialmente controlado y habría de basar toda su defensa en el fuego de sus piezas más ligeras escondidas en los fosos, renunciando a enfrentarse directamente desde los adarves o las defensas altas a la artillería francesa.

Sin embargo esta decisión estratégica no era unánimemente compartida y el arrollador asalto francés a Salsas la Vieja en 1496 provocó un razonable desánimo en las fortalezas de la frontera.

Para animar a las tropas de frontera con Francia, escribían, en noviembre de 1496, los RRCC al capitán de Fuenterrabía, donde se estaban construyendo baluartes y defensas bajas a la manera de Salsas ${ }^{16}$, y le decían: «ya havreys sabido lo de Salsas y como la gente francesa tomando descuidada la nuestra lo entraron y asi no es razon que se tenga la templanza que fasta aqui se ha tenido ${ }^{17}{ }$. Con templanza o sin ella, algunos artilleros españoles debíeron mostrarse entonces más propensos a basar la defensa en contestar al enemigo cañón contra cañón desde lo alto de las fortalezas. Esta es al menos la conclusión que se desprende de la carta que el 1 de agosto de 1498 envía desde Perpiñán el comendador San Martín, futuro capitán general de la artillería española: «Yo soy ydo muchas veses e agora a tres dias a Salsas que tenían fecho el çimiento de la mitad del moneo de la torre que esta entre los dos baluartes e desinado las lonbarderas e todo lo que en ello se ha de haser e por capitulos con el governador e maestre Ramiro los quales enbio a vuestra altesa y el traslado dellos dexo al capitan general por que lo faga esecutar ... ya tengo dicha toda mi opinion al governador de lo que ha de faser para estar seguro en Salsas que una vez haga acabar el muro e las defensas de arriba asy de las torres como de los adarves que segun los enfermos que ay en ella e la poca gente me paresçe que nunca estara segura fasta que las dichas defensas de arriba esten fechas». En la misma carta San Martín especifica la artillería entregada para la defensa de Salsas «que por memorial de vuestra altezas me fue hordenada que son dos culebrinas e ocho sacres en ques una de las medias culebrinas pero todos tiran una pelota e veynte e quatro ribadoquines e sesenta e tres sacabuches buenos e adovados e veinte e syete lombardetas de metal e quatro de feirro que son treynta e una con dos servidores cada una e todo en horden para tirar ${ }^{18} \gg$.

Pese a las reticencias del comendador San Martín la obra de Salsas continuó primando las defensas bajas y los baluartes avanzados y cuando en 1503 se produjo el enfrentamiento entre españoles y franceses de forma simultánea en Salsas y en Nápoles fue la artillería ligera, las espingardas principalmente, y la eficacia de las minas de Pedro Navarro, las que garantizaron la victoria a las tropas del Gran Capitán en Italia. Las cincunstancias del asalto a Salsas y el propio proceso constructivo de esta fortaleza han sido referidas por nosotros en un estudio de $1998^{19}$ que incluía por primera vez la publicación y la transcripción completa del plano que sobre el asedio levantó el capitán Gonzalo de Ayora y que aquí reproducimos nuevamente. En síntesis puede decirse que el desenlace del encuentro era ya previsible de antemano; los franceses con gran despliegue de artillería eliminaron cualquier defensa de «la cinta arriba», demoliendo prácticamente las partes altas del edificio, pero tuvieron serias dificultades para tomar los fosos y emplazar allí sus gruesas piezas; fracasaron igualmente sus intentos de mina y sufrieron importantes pérdidas cuando tras tomar el baluarte de la puerta este fue volado por una mina de Ramiro López que sí explotó.

Sin embargo, aparte de las fuentes que utilizamos en el citado estudio, para el objeto de este artículo, merece la pena considerar tres documentos inéditos sobre Salsas, que incluimos ahora en el anexo. El primero de ellos corresponde con la carta de 11 de octubre (documento

\footnotetext{
16 COBOS y DE CASTRO, 2000b.

17 Carta de los RRCC a Diego Lopez de Ayala dada en Burgos el 8 de noviembre de 1496.ANT. Caja 18, no 84.

18 AGS, GA, leg 1315, fol 186.

19 COBOS y DE CASTRO, 1998b.
} 
4) que envía Fernando el Católico al duque de Alba en respuesta a los informes que éste le había hecho llegar y que eran básicamente las cartas de Ayora. Hasta ese momento la actitud de Fernando el Católico había sido quizá demasiado prudente, y pese a haber reunido un considerable ejército, no había atendido a las peticiones de ayuda de la fortaleza y del propio duque de Alba, forzando a la guarnición de Salsas a resistir más allá de lo que hubiera sido necesario. La carta que conservamos es precisamente la contestación a un escrito del duque de Alba que acompañaba a un memorial, posiblemente una de las cartas de Gonzalo de Ayora, y en el que le contaban la situación desesperada del baluarte de la puerta. En ella, el rey Católico le pide al duque que ordene al informador (¿Ayora?) que averigue si las lombardas «están a media cava o abaxo ygual con la cava o al borde della y si tira a las defensas baxas o a lo alto o al medio de la cerca y que mire bien que es lo que esta derribado de Salsas y de donde tiran los de dentro», le pide igualmente que le informa cuanta gente vino con la armada francesa, que «si es gente de Saboya yo creo que vale poco». Le comenta que espera la llegada de la flota que está preparada en Málaga y que ha ordenado construir un baluarte, por el comendador San Martín, en Port Vendres para que pueda abrigarse, y le autoriza a intentar un ataque nocturno con mil hombres escogidos a «la estancia que los franceses tienen entre Perpinan y Salsas contra la puerta de Salsas», intentando en la misma operación apoderarse de la artillería francesa que esté en el foso, introduciéndola dentro de Salsas. Este ataque lo justifica Fernando el Católico no tanto por aliviar la situación de la fortaleza como porque «ya teneys ahy (Perpiñán) tanta gente (que) si no se acometiere alguna cosa de afrenta y ahun de algun peligro ... los de Salsas enflaquecerian».

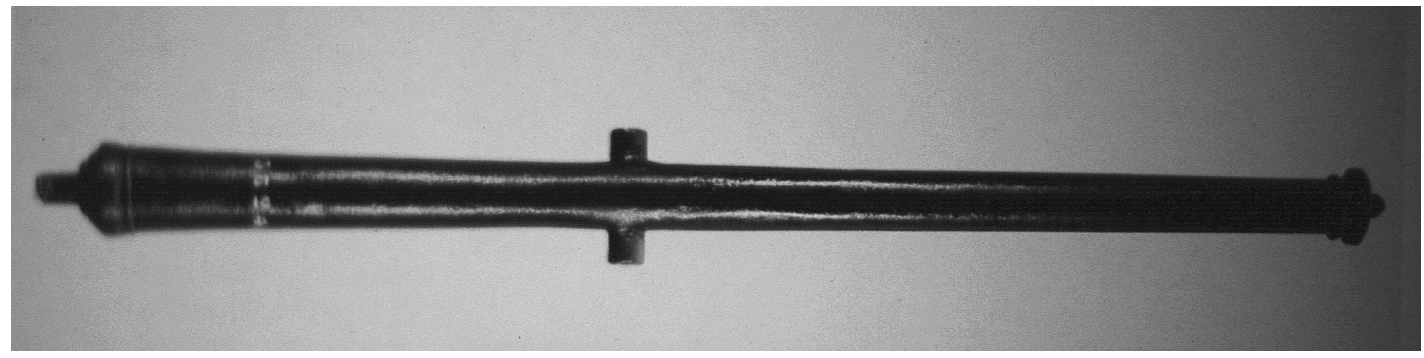

Figura 3. Medio ribadoquín procedente de Valladolid (¿Medina del Campo?) de finales del XV o principios del XVI. Museo del Ejército 3.310, 64.

Sin embargo las cartas de Ayora de los días posteriores, que ya reproducimos parcialmente en el citado estudio, dan cumplida información sobre los daños y la posición de la artillería francesa, pero no informan de ningún ataque nocturno español y es el plano que acompañaba a las cartas el que indica expresamente que la artillería francesa que batía la puerta se retiraba por las noches y se volvía a montar por las mañanas, precaución que imposibilitaba el éxito de la estrategia española. Además, la carta del rey pedía al duque que procurase que los de Salsas hicieran las señas que estaban previamente pactadas y no otras, lo que sin duda provocaba cierta incertidumbre sobre la verdadera situación de los defensores, más aún cuando incluso el rey tenía noticia de que parte de la guarnición estaba descontenta, posiblemente porque no entendían que el importante ejército reunido en Perpiñán no acudiera en su auxilio y se les sacrificase de ese modo. Coincide por tanto este dato con otras informaciones ${ }^{20}$ que indican que la fortaleza, que ya había resistido los «treinta o cuarenta

20 Ver documento $n^{\circ} 6$. 
dias fasta ser socorrida» comprometidos en el encargo a Ramiro López, habría caido finalmente si no hubiesen llegado las tropas del Duque de Alba a levantar el sitio, el 20 de octubre de 1503, abandonando los sitiadores «más de 4.000 pelotas de hierro».

El sitio de Salsas puede por tanto considerarse como el episodio militar más trascedente de su época para el posterior desarrollo tanto de la fortificación como de las técnicas poliorcéticas y especialmente la artillería y las minas. El importante destrozo que produjo la artillería francesa sobre la fortaleza española incita a pensar, en un principio, que el poder de fuego del ejército de Luis XII fue una sorpresa para las tropas españolas. Sin embargo, hay muchos otros aspectos que permiten deducir que la fortaleza fue expresamente diseñada para sobrevivir con éxito a tan abrumador ataque. Por un lado no conviene despreciar la eficacia de los espías de Fernando el Católico y es casi seguro que, al igual que en 1488, estuvo siempre informado del impresionante poder de la artillería de su principal enemigo en Europa. Hemos visto además como los Reyes Católicos, pese a conocer el potencial enemigo habían optado, al menos desde 1495, por fundir mayoritariamente piezas de artillería de pequeño calibre, más útiles para guarnecer las fortalezas y dotar de mayor movilidad a los ejércitos reales, y la desventaja de no tener mucha artillería gruesa para asaltar fortalezas venía compensada por el desarrollo de las técnicas de mina que tan eficaces fueron en la toma de los castillos de Nápoles.

El segundo documento inédito que anexamos sobre Salsas es una relación de la artillería que guarnecía la fortaleza en 1502 (documento 5), que puede tomarse como buena aproximación a la dotación que tenía la plaza cuando fue cercada y que evidencia la estrategia castellana. Apenas hay piezas de calibres gruesos o medios: 5 lombardas con escasas pelotas de piedra y 2 falconetes y dos medias culebrinas, hechas por fundidores alemanes, con sus 800 pelotas y 2 servidores por pieza. El calibre pequeño está, sin embargo, ampliamente representado por 7 cerbatanas de hierro y munición de piedra, y 40 piezas de las fundiciones castellanas, 12 de ellas llamadas san Migueles y san Martines, con proyectiles de apenas 4 libras y escasamente 350 pelotas, y otras 28 piezas de calibre aún más pequeño (ribadoquines y cerbatanas), con 4.600 pelotas. Esta artillería, que no es poca para una fortaleza como Salsas, no permitía en ningún caso, contestar al fuego francés cañón contra cañón, ni parece ser que esta fuera, como ya hemos dicho, la intención de Ramiro López. La preocupación tanto del capitán Gonzalo de Ayora, como del propio Fernando el Católico por conocer si los franceses disparaban de la cinta abajo, es indicativa de que todos eran conscientes de que el principal valor defensivo de la fortaleza residía en sus líneas de fuego ocultas por el foso, como si se hubiera dado por perdida la batalla en las defensas altas incluso antes de que empezara el ataque francés. A este propósito el armamento principal del castillo no era tanto la artillería, que aún con poco calibre podía desmontar las defensas de los cañones enemigos que se asomaran al foso, como las armas de fuego ligeras y personales de los infantes, de las que Salsas tenía ya en 1502, 288 entre «sacabuches» y espingardas, con 24.000 pelotas que le permitieron cubrir con un nutrido fuego el foso desde galerías intramuros, baluartes y caponeras. De esta forma si la batalla artillera contra el castillo la ganó ampliamente el ejército francés, en la batalla de los fosos, casi de fusilería, y en la batalla subterránea de minas, la tecnología tanto armamentística como arquitectónica de los españoles fue superior ${ }^{21}$, permitiendo que el castillo resistiera en una situación aparentemente insostenible.

Finalmente, el tercer documento inédito sobre Salsas (documento 6) relata las circunstancias del magnífico repliegue francés tras fracasar el asalto e indica claramente hasta que punto, tanto para los franceses como para los españoles, la pérdida o conservación de la artillería era esencial en el desenlace de la guerra. Así los franceses abandonaron el cerco en

21 El documento 6 que anexamos sugiere que los franceses realizaban, al menos en algún caso, minas con cuentos (encuentos) de madera para prenderles fuego y no minas explosivas como las españolas. 
cuanto creyeron que podían perder la artillería, saliendo «con todo su ejercito con toda su artilleria delante», refugiándose en la sierra, y al día siguiente, «de mañana tomaron su camino ordenadamente y toda su artilleria delante», rechazando los ataques de las vanguardias españolas. De esta forma «los grandes que con el rey nro señor yvan parescioles que no era razon de seguir mas aquella gente que yva muy determinada y ordenada especialmente ... y asi acordaron con su Alteza de se bolver de que peso a muchos porque diz que si aquel dia los siguieran y se fiziera como se devia de fazer aquel dia se acabara la guerra con Francia. Tachan mucho en esto el descuido o negligencia de nuestra gente que diz que si dos horas antes salieran los despacharan del todo....(aunque)...ciertamente diz que los franceses mostraron gran coraçon en su salida y bien todo lo fizieron como buenos guerreros pero si los nuestros no durmieran tanto...»

\section{APUNTES PARA EL ESTUDIO DE LA ARTILLERÍA DE LOS REYES CATÓLICOS.}

En el estudio de la época de transición, tanto de la artillería como de las fortalezas, quedan todavía importantes lagunas. Es mucha, sin embargo, la documentación conocida y en algunos casos, como algunos de los documentos que aquí anexamos, de notable precisión. En el caso de las fortificaciones, a falta en cuanto a España se refiere, de tratados a lo Francesco di Giorgio, se conservan espléndidos ejemplos de edificios construidos en esta época que, junto con la documentación que los data fehacientemente, permiten establecer las claves de un proceso evolutivo directamente vinculado al propio desarrollo de la artillería. Desgraciadamente respecto a las piezas de artillería que emplazaron estos edificios o que se reseñan en los diversos inventarios conocidos y publicados hasta ahora ${ }^{22}$, la falta de restos materiales es absoluta. Así, las excavaciones realizadas tanto en la Mota, como en Ponferrada, no han aportado hallazgos determinantes ${ }^{23}$. En Ponferrada sólo se ha localizado una pelota de hierro de $6,5 \mathrm{cms}$. de diámetro que pertenece posiblemente a un ribadoquín grande y una caña de lombarda de $13 \mathrm{cms}$. de calibre de hierro forjado que si bien presenta alguna novedad en su forma de construcción ${ }^{24}$, no se corresponde con las piezas fundidas para su asalto en 1486. Por su parte en la Mota todas las piezas que se han encontrado desde principios del siglo XX corresponden a trabajos de hierro forjado, sin rastro alguno de piezas de fundición. No se han realizado tampoco análisis metalúrgicos ni se ha establecido ningún programa sistemático de investigación que permita establecer la composición real de las piezas que se llamaban de fuslera, o de metal, y si ambas denominaciones eran o no una misma cosa cuando ambas denominaciones coinciden en un mismo inventario ${ }^{25}$.

Es poco, por tanto, lo que podemos avanzar sobre lo publicado por Arátegui en 1887 y desconocemos incluso el aspecto externo que pudieron tener las piezas fundidas por los Re-

22 En COBOS y DE CASTRO,1998a:139, publicamos el inventario de la artillería que había en el castillo de Cuéllar a la muerte en 1526 del segundo duque de Alburquerque que reseña piezas de fuslera y de metal que proceden de artilleros y fundidores de Olmedo y Medina del Campo. También es significativa la referencia de la artillería que entregó Fernando el Católico al señor de Coca, Antonio Fonseca, en 1505: «yo os ove mandado dar de la artilleria de Medina del Campo ciertas piezas de artilleria que yo mandara fundir dando vos el metal con que pudiesen facer otras tantas de nuevo y demas desto yo vos mande dar otras cinco piezas de artilleria». Ibidem 237.

23 Excavaciones desarrolladas por los Planes Directores de Restauración dirigidos por el arquitecto Fernando Cobos desde 1992 en La Mota de Medina del Campo y desde 1994 en Ponferrada, cuyas obras están actualmente en curso. En el caso de la Mota aparecieron cañones de hierro forjado en las excavaciones de 1917, 1930 y 1939, algunos de ellos depositados en el alcázar de Segovia y otros inexplicablemente desaparecidos.

24 La caña está construida por cuatro láminas de unos 3 a $5 \mathrm{~mm}$. de espesor, curvadas hasta formar media caña y de toda la longitud de la pieza, que se solapan tapando juntas y van reforzadas por bridas, compuestas de pletinas de $3 \mathrm{~mm}$. y aros de $15 \mathrm{~mm}$. de grosor, separadas entre si unos $9 \mathrm{cms}$.

25 El citado inventario de 1526 de Cuéllar (nota 22) por ejemplo. 
yes Católicos en el siglo XV. Hemos sugerido anteriormente ${ }^{26}$ que algunas piezas que conserva el Museo del Ejército ${ }^{27}$, podrían corresponderse formalmente con los ribadoquines típicos de finales del XV, aunque estas piezas están clasificadas como hierro forjado sobre alma. En este sentido el propio significado que ha llegado a tener del término fuslera, - fruslera-, despectivo y más relacionado con el latón que con el bronce podría indicar la mala calidad e impureza de las primeras aleaciones de fundición y justificaría la tendencia detectada en toda Europa a finales del XV hacia la fundición de piezas de hierro, tendencia que a su vez dejó paso en el s. XVI a una nueva generación de piezas de bronce de mayor calidad. Queda, sin embargo, por caracterizar metalúrgicamente la aleación empleada en el s.XV y saber en que momento se pudieron fundir piezas de hierro en España y cuando se pudieron emplazar en las troneras que ahora conservan vacías nuestras fortalezas de transición.

26 CoBos, 1994:336.

27 Museo del Ejército 3,310,64 y otras nueve piezas con números 3.009/12/13/20/10/11/21/22/23/24 del Catálogo de 1908. 


\section{DOCUMENTOS}

\section{DOCUMENTO 1}

Zamora 1475

(ADA. C-62-54)

Escritura otorgada por el conde de Alba de Liste y otros caballeros en cuya virtud se obligaron a restituir al duque de Alba 5 lombardas grandes y medianas con sus servidores y 2 ingenios que les había prestado para batir el alcázar de Zamora cercado por el rey. Zamora, 21 de diciembre de 1475.

«Plogo y place de en prestar y presto una lombarda gruesa con dos servidores e otra lombarda menor que ella con sus servidores e otra lombarda mediana asi mismo con sus servidores e otras dos lombardas menores que estas con sus servidores e dos ingenios uno grande e otro menor».

«o de pagar de la moneda que corra al tiempo de la paga por cada uno de los dhos pertrechos la cantidad de mrs que se sigue en esta guisa por la dha lombarda mayor $150.000 \mathrm{mrs}$ e por la otra menor que ella $90.000 \mathrm{mrs}$ e por la otra tercera $50.000 \mathrm{mrs}$ e por cada una de las otras menores $20.000 \mathrm{mrs}$ e asi mismo devolver e darle los dhos dos ingenios o le dar otros tan buenos o la pagar por ellos 150.000 mrs de la dha moneda».

\section{DOCUMENTO 2}

Estracto de las cuentas de la toma de Ponferrada en 1486

AGS. CMC, $1^{\text {a }}$ epoca, leg 108.( ya reproducido parcialmente por Arántegui en 1887)

Que se dio mas a Juan Gomes e a $\mathrm{P}^{\circ}$ Gra. e a $\mathrm{Ju}^{\circ}$ Dasa e a Juan de Umanes e a $\mathrm{P}^{\mathrm{o}} \mathrm{A}^{\mathrm{o}}$ pedreros que estuvieron desde 15 de mayo fAsta 24 de junio que son 39 dias seguidos para sacar piedras de lombarda no fizieron en todo el dho tiempo ninguna cosa asy porque el artilleria no era llegada como porque no se fallaban canteras e despues mandamos haser yguala con los dhos pedreros e ellos buscaron otros de su oficio e que fiziesen quantas piedras pudiesen e por cada una piedra de las que diesen escodadas fechas e limpias para tirar les daria $75 \mathrm{mrs}$ los quales fizieron 275 piedras limpias e buenas a vista de maestre Ramyro e de los otros artilleros del Rey nuestro señor demas de otras que les desecharon que monto en ellas al dho precio de $75 \mathrm{mrs}$ cada piedra $19.875 \mathrm{mrs}$ e con los dhos 7.800 susodhos que se les dio de las jornales que ganaron son estos $27.675 \mathrm{mrs}$ los quales se les pagaron en dineros contados.

Que se dio e pago mas a Gracia Alvarez vecino de Benavente que tovo cargo de hacer los moldes e medidas para pelotas e otras cosas necesarias a los ribadoquines el cual sirvio desde 3 de junio hasta 20 de julio que son 47 dias que le monta en ellos a rason de 30 cada dia $1.410 \mathrm{mrs}$ los quales se le pagaron en dienros contados.

Que se dio e pago mas a Andres Sanchez campanero vecino de Mançanilla e a $\mathrm{m}^{\circ} \mathrm{P}^{\mathbf{o}} \mathrm{e} \mathrm{a} \mathrm{m}^{\circ} \mathrm{Ju}^{\mathrm{o}} \mathrm{su}$ hermano vecinos de Çamora que tovieron cargo de fundir e haser todos los ribadoquines que pudiesen para el artilleria del Rey nro señor con los cuales mandamos avenir e ygualar que por cada ribadoquin que fundiesen e saliese bueno e limpio e tirase con el aprueva dos tiros que se les diese myl mrs e que ellos pusiesen para las fundiciones toda costa de leña e carbon e molde e madera e otras cosas ecebto

el cobre e estaño e que el dia de la fundicion se les diese fuelles e ombres que follasen los quales fundieron e fisieron 17 ribadoquines los quales tres dellos llevaron a don Diego Lopez de Haro a Gali- 
cia e otros tres que quedaron en la fortaleza de Ponferrada e los 11 se entregarona maese Ramiro e Salvatierra que los llevaron con el artilleria a Medina del Campo asy que se dieron a los dhos fundidores por los dhos ribadoquines $17.000 \mathrm{mrs}$ e mas otros $1.500 \mathrm{mrs}$ que les mandamos dar para ayuda de su costa porque avian estado muchos dias e pedrian en ella que son $18.500 \mathrm{mrs}$ e que costaron mas seys ombres que follaron en 20 fundiciones que se hicieron cada fundicion tres reales e medio real cada peon que son 60 reales que montan $1.860 \mathrm{mrs}$ e $500 \mathrm{mrs}$ que costaron el alquiler de tres pares de fuelles asy que son todos $20.860 \mathrm{mrs}$ los quales se les pagaron en dineros contados por nro mandado.

Que costaron 20 quintales de cobre que A $^{\circ}$ Quintanilla mande comprar en la feria de Medina del Campo del mes de mayo de dho año de 86 porque no faltase cobre asy para las fundiciones de los ribadoquines como para algunas lombardas si quebraran e para otras cosas necesarias de la dha artilleria e costo cada quintal dello $2.250 \mathrm{mrs}$ que monto en los dhos 20 quintales de cobre $45.000 \mathrm{mrs}$ el cual dho cobre que no se gasto e mas de lo que se compro en Burgos otros cientos quintales e se entrego todo al dho maese Ramiro e Salvatierra e los llevaron con el artilleria.

Que fise comprar yo el dho Quintanilla en la feria de Medina de Rioseco del mes de (blanco) cinco quintales e 16 libras de estaño que fue menester para las fundiciones de los dhos ribadoquines que costaron a $2.448 \mathrm{mrs}$.

Que se compraron mas en Benavente un quintal e medio de plomo que costo $1.100 \mathrm{mrs}$.

Que se compro mas otro quintal de plomo en Valladolid que costo $800 \mathrm{mrs}$.

Que costo mas en la dha feria de mayo de Medina del Campo 8 quintales e 80 libras de plomo que costaron $6.600 \mathrm{mrs}$ a rason de $750 \mathrm{mrs}$ el quintal. (Este plomo sobro fasta 2 quintales e medio en una pasta e mas de 300 pelotas de ribadoquines fechas los qual todo quedo en Ponferrada).

Que compraron en Benavente en 5 de mayo del dho año dos quintales de fierro para faser las guarnisiones de las cabritas e para otras cosas que fueron alli menester de refaser e costaron 700 (e otrosy se compro mas otros 4 quintales e medio de fierro en los Barrios de Salas en 10 de julio que costaron $1.130 \mathrm{mrs}$ que se compraron mas otros cinco quintales $\mathrm{f}^{\mathrm{o}}$ en valde Valduerna que costaron $1.250 \mathrm{mrs}$ a rason de 250 el quintal que se compraron mas en la dha feria de Medina del Campo 7 quintales de $\mathrm{f}^{\mathrm{o}}$ fercuyl que costaron 2.240 a razon de 320 el quintal e otros 5 quintales de $\mathrm{f}^{\mathrm{o}}$ llano que costaron 1.000 a 300 el quital asy que costo todo el dho fierro $6.810 \mathrm{mrs}$.

Que se compro mas en la dha feria quintal e medio de azero fino que costo $1.125 \mathrm{mrs}$ a rason de 750 el quintal.

Que se compro mas otros dos quintales e medio de azero redondo que costaron 912 mrs e medio a rason de $465 \mathrm{mrs}$ el quintal.

Que se compro en Valladolid en 13 de abril de 86 años una carreta grande fuerte muy buena para el artilleria e para llevar las lombardas de Dueñas del conde de Buendia que costo 4.500 mrs e mas otros 400 mrs que costo adobar e reparar que son $4.900 \mathrm{mrs}$ la qual dha carreta se compor de Geronimo de Vuines regidor de Valladolid que la tenia e el en que traya muelas grandes para molinos.

Que se compraron mas otras dos carretas grandes e nuevas e herradas en la cibdad de Burgos para traher la lombarda del conde de Castrojeriz e dos servidores e otros aparejos que costaron $10.000 \mathrm{mrs}$ segun lo juro Salvatierra que las compro.

Que se compraron mas en Benavente otras dos carretas de $\mathrm{P}^{\mathrm{o}}$ Mrs vecino de Villalon herradas e buenas e nuevas para llevar ciertas escalas e ribadoquines del artilleria las quales costaron $4.000 \mathrm{mrs}$.

Que se compraron mas en la dha Benavente 12 carros para llevar el almazen e polvora e ribadoquines e maromas e para despues servirse dellos e de los bueyes en el Real para las cosas que fuesen menester que costaron $2.900 \mathrm{mrs}$.

Que costaron 200 palas de plomo que se compraron en Benavente para el Real para las cavas e estançias $1.500 \mathrm{mrs}$ a rason de $700 \mathrm{mrs}$ e medio cada pala. (Estas palas se entregaron a maese Ramiro).

Que costo hazer una cabrita fuerte que se hizo en Benavente syn el fierro e clavazon e madera salvo las manos de los carpinteros e del ferrero $600 \mathrm{mrs}$.

Que se compraron en la dha Benavente ciertos maderos grandes de olmo que serian mas de 20 para las escalas e para las cabritas e para los bancos de ribadoquines e para otras cosas que se fizieron en la dha Benavente que costaron 3.500 mrs.

Que se cortaron en los Barrios de Salas e en Molina Seca e al derredor los Barrios de Salas una legua en ciertas aldeas mas de 700 olmos grandes e robles e encinas e nogales e vigas e logares grandes que se tomaron e le truxo todo para el lugar de Campo ques junto con Ponferrada e se labro e se fizo dello las mantas e reparos e estacadas e cercas y otras cosas que fue menester para la dha artilleria 
la qual dha madera no se pago ninguno ecebto a tres iglesias de los dhos Barrios que se cortaron ciertos olmos grandes e encinas e robles por lo qual se les dio $2.390 \mathrm{mrs}$. (Toda esta madera se labro de hacha e se metio mucha della en la fortaleza de Ponferrada e la otra toda se gasto en el ospital que quemaron los del conde de Lemos e le mandaron haser sus altezas).

Otros gastos por menudo.

Que costaron la costa de quatro carros que vinieron cargados desde Medina del Campo hasta los Barrios de Salas de hierro e cobre e $\mathrm{az}^{\mathrm{o}}$ e plomo e otras cosas $414 \mathrm{mrs}$ que se gastaron por menudo asy en sego para los dhos carros como en portazgos que pagaron por el camino en otras cosas.

Que costo mas alquiler de dos pares de bueyes con dos carros que traxeron seys ribadoquines que se avian fundido en Benavente $465 \mathrm{mrs}$ por los poner en Barrios de Salas que avian ydo con la dha artilleria.

Costaron faser ciertas fundiciones e fornos para ellas demas de lo que dho es que Ochoa dezia fizo haser en Benavente a los fundidores porque no estava bien fecha los que ellos tenian $558 \mathrm{mrs}$ segun lo dio el dho Ochoa por menudo.

Que se hallo por cuenta que cuando vieron en todos los dias que se labraron las maderas para los reparos e mantas e curueñas de lombardas e coçes? e entre coçes e estacadas e cabritas e otras cosas muchas que se labraron en el artilleria asy en lo labrar como en lo cortar en los montes 590 hacheros los quales se cogian cada dia asy como heran menester de los peones que estavan en el real que heran oficiales del dho oficio a los quales se dio de jornal de mas del sueldo que se les davan medio real a cada uno cada dia que monto en ellos 9.145 mrs.

Que se compraron de Gavilanes estalador? 30 quintales de polvora delgada fina e muy buena e 10 quintales de polvora gruesa por precio de $2.300 \mathrm{mrs}$ cada quintal de la polvora delgada e $1.700 \mathrm{mrs}$ de cada quintal de polvora gruesa puesto en Valladolid en su casa que monta en los dhos 30 quintales $69.000 \mathrm{mrs}$ e en los dhos 10 quintales $17.000 \mathrm{mrs}$ que monto en los dichos 40 quintales al dho precio $86.000 \mathrm{mrs}$ a esto de mas e allende de otros 30 quintales quel rey e la reina nros señores mandaron comprar del dho Gavilanes en Medina del Campo e que los pago alli Francisco Gomez de Sevilla los quales asi mismo se trajeron al Bierzo e no se pone aqui por data porque fueron puesto en la nomina que se fizo en Medina sin mandamiento del rey e de la reina nros señores para el dho tesorero a bueltas de otros gastos que alli se hizieron contenidos en la dha nomina. (Esta polvora que se compro de Gavilanes se gastaron en toda la guerra 25 quintales 80 libras con los 12 quintales que se le mandaron a don Diego Lopez a Galizia e con otros 2 quintales que llevo don Fernando a Villafranca e sobraron 45 quintales los 10 quintales dellos quedaron en la fortaleza de Ponferrada e los 35 quintales llevo maese Ramiro e Salvatierra con el artilleria).

Que se compraron en Benavente de $\mathrm{A}^{\mathrm{o}}$ de Salamanca vecino dende 80 libras de polvora fina que costaron $1.900 \mathrm{mrs}$.

Costaron 850 dados de fierro para pelotas de ribadoquines grandes e chicos uno con otro a dos mrs e medio el par que monto en ellos $1.125 \mathrm{mrs}$.

Que se fizieron en Benavente dos guarniciones para las cabritas de las lombardas que pesaron 350 libras de hierro $900 \mathrm{mrs}$ solamente las manos sin el hierro que le dio las quales hizo Perote cerrajero de la dha Benavente.

Que costo traher la lumbarda grande del conde de Castro que se dize la cozinera e dos servidores della e otras cosas desde Castrojeriz hasta Palacios de Valduerna asy en alquileres de ombres e bueyes como en otros gastos e costas segund lo dio por menudo Salvatierra que lo traxo $8.000 \mathrm{mrs}$.

Que costo traer la otra lumbarda del conde de Buendia con sus servidores desde Dueñas hasta Palacios de Valduerna 5.000 mrs segun lo dio por menudo Pedro de las Cuevas que la traxo.

Que se dieron mas a Juan Garcia de Salvatierra para levar las lombardas e pasabolantes e otras cosas del conde de Benavente e de doña Maria Çapata desde Ponferrada hasta sus casas $3.500 \mathrm{mrs}$.

Que dio e pago mas a Gavilanes estalador por 30 quintales de polvora la mitad delgada e la mitad gruesa que le mandamos comprar para que llevase los dhos conde de Benavente e $\mathrm{A}^{\mathrm{o}}$ de Quintanilla a don Diego Lopes de Haro a Galizia $60.000 \mathrm{mrs}$ a rason de $2.000 \mathrm{mrs}$ cada quintal uno con otro.

Que dio e pago mas a $\mathrm{A}^{\circ}$ Pardo mercader vecino de la cibdad de Burgos 90.000 mrs para cierto cobre que le mandamos comprar e enbiar al conde e $\mathrm{A}^{\mathrm{o}}$ de Quintanilla para ciertos ribadoquines que se han de faser. 


\section{DOCUMENTO 3}

Tours hacia 1488

(RAH. CSC. N-22, fol 7).

En la casa donde esta el artilleria en la cibda de Turs estan los tiros que se siguen los quales son todos de fuslera que no ay ninguno de yerro.

Asta 16 lombardas que tienen los 8 de luengo 16 palmos y medio y en la boca de hueco 2 palmos tiran piedra de yerro que pesa ciento quintales y medio cada una y llena de polvora 120 libras y puede pasar 20 ó 30 pies de muro y tira 2 leguas de Francia y tiran cada un dia 12 veces y pesa el cajon de cada lombarda 170 quintales. Los otros 8 tienen de luengo 13 palmos y medio y en lo hueco de la boca 2 palmos estas tiran piedras que pesa cada una 120 libras de piedra y llena de polvora se tira 80 libras y puede romper 15 ó 18 pies de muro y pesa cada cajon 140 quintales.

Ay mas 24 tiros que se llaman cañones que tiran desde encima de los carretones asi como estan encavalgados y tienen de luego 10 palmos y en la boca un palmo y dos de dos y tira de piedra de yerro de 80 libras y llena de polvora cada uno 25 ó 30 libras y pasa de muro 15 ó 18 pies y puede tirar cada dias 24 ó 28 tiros y pesa cada uno 30 quintales.

Estan otros 12 cañones que tiran piedras que son asi de luengos como los dichos y pesa cada piedra 60 libras de piedra llena de polvora cerca de 25 ó 30 libras y pasa de muro 12 pies y tira asi mismo sobre los carros y pesa cada uno cerca de 25 quintales.

Estan mas 4 tiros que se llaman serpentinas y tiene cada una sin el servidor de luengo 18 palmos y uno en la boca tira piedras de yerro que pesan 56 libras y llena de polvora cada una con su servidor 50 libras pasa de muro o fuertes baluartes 18 pies y tira a mas de 2 leguas y tira sobre los carros.

Asta mas 41 culebrinas las unas mas gordas que las otras. Las mayores tienen 17 palmos y en la boca hasta un durasno grueso y otras tienen 12 palmos y otros 10 palmos y medio los mas pequeños y son los mayores de 24 quintales cada una y otros de 14 quintales y otros de 12 y otros de 8 y tiran piedras de plomo cada una de su calidad estas son para romper batallas y tiran sobre los carros como las traen los cavallos.

Todos estos tiros estan en sus carros y puesto todo su aparejo que no tiene que hacer sino traer los cavallos y andar con ellos y tiene su provision de polvora y piedras de yerro y de plomo y de piedras asaz para que pueda bien desbastar.

\section{DOCUMENTO 4}

Salsas 1502

(AGS. GA, leg 1315, fol 98.)

Relacion de las municiones y artilleria que ay en la fortaleza de Salsas hasta oy fin de octubre de DII años.

Artilleria.

3 san Martin y para ellos 150 pelotas y moldes para hacer mas. (Segun Arategui, pag 337, los San Martin pesaban 3 a 4 quintales y el proyectil de 3 a 4 libras; esto es ribadoquines grandes).

9 san Migueles y para ellos 200 pelotas y moldes para hazer mas. (Segun Arategui, pag 337, los San Mifuel pesaban 4 quintales y el proyectil de 3 a 4 libras; esto es ribadoquines grandes).

11 ribadoquines y para ellos 2.300 pelotas y moldes para hacer mas.

17 cerbatanas de metal y 25 servidores y para ellos 2.300 pelotas y moldes para hacer mas.

4 lombardas de metal y 8 servidores aun no tiene piedras porque agora se ha acabado.

2 falcones de las que se hizieron ay en persona los fundidores alemanes y 400 pelotas y sus moldes.

2 medias culebrinas que ha ehco ay los dhos fundidores y 400 pelotas y sus moldes.

64 sacabuches y para ellos 8.000 pelotas y sus moldes.

1 lombardeta de hierro de 6 palmos con su servidor y 60 pelotas de piedra para ella.

7 cebratanas de hierro con 14 servidores y 200 pelotas de piedra.

224 espingardas y para ello 16.000 pelotas y unos moldes.

50 buzanos para traer piedras y pelotas los espingarderos.

61 piezas de plomo que pesan 64 quintales e 20 libras. 
10 molineros de hierro para san martines y san migueles e ribadoquines demas de los que ellos tienen.

150 barriles de polvora y los 6 dellos son de afinada para espingardas.

11 costales de salitre por afinar.

10 costales y 3 barriles de açufre.

18 costales de carbon de sauce.

18 medidas de hoja de Milan para casar los tiros.

500 cartuchos de papel e mas una resma para hacer mas de lo de la ... mayor.

12 aludas de cuero para llevar polvora de una parte a otro por la fortaleza.

9 docenas de atacadores gruesos y delgados de la suerte que son menester para los tiros.

De acero que ay 15 quintales.

74 madejas de yerro en que ay 50 quintales.

Otros 20 quintales de yerro menudo.

Armas.

30 vallestas gruesas que se trajo de Aragon y 2.000 pasadores gruesos para ellas y mas que se hacen.

6 tornos para las armas.

6 guindallas para las armas.

Otras 80 vallestas, 60 que se traxo de Castilla e 20 que se avian tomado del castillo.

200 docenas de almacen que se avia tomado del castillo de lo mas grueso.

15 caxas de almacen que se truxo de Castilla en que avia 25 tiros.

Otras 15 cajas de almacen.

Una resma y media de papel y 15 libras de cola para hacer plumas a los pasadores.

200 ovillos de lo que se tomaron del castillo para hacer cuerdas de vallestas.

3 botas de ovillos de dho ylo de lo que tenia Ruiz en que ay 1.500 ovillos.

Media arroba de cera para hacer cuerdas de vallestas.

100 piastrones e 100 cercelleras e 100 armaduras de brazo izquierdo que se tomaron del castillo.

80 corazas que se trajeron de Castilla.

145 celadas con sus barbotes que se trajeron de Castilla.

Mas otras 47 celadas con sus barbotes todo desguarnecido que tenia Ruiz Casafranca.

80 paveses que se tomaron del castillo.

Mas otros 200 paveses y escudos que se traxo de Castilla.

Otros 120 paveses que tenia Ruiz desguarnecido de lo de Casafranca.

200 piecas de le mas de las del castillo.

114 lanzas ginetas.

33 lanzones cortos.

50 lanzas ginetas sin yerros.

300 ondas de cañamo.

6 ollas grandes de yerro fundido.

4 almirezes de yerro fundido.

2 calderos de yerro fundido.

1 mortero grande de piedra para afinar polvora.

11 calderas de cobre.

24 cantaras de cobre.

2 cazos de cobre.

10 gindaletas de canamo gruesas.

30 guindaletas de canamo de seda.

1 quintal e 10 libras de canamo de cerro.

150 docenas de soga desparto.

196 azadones.

98 picos.

98 palas.

46 achas vizcainas.

150 pares de zapatos y espartenas. 
18 escudillas de palo.

24 linternas.

20 candiles.

5 suelas de agujetas dermora.

70 camas de ropa.

150 costales.

30 antorchas de cera.

2 quintales de candelas de sevo.

Ay en meleznas y agras y conservas y otras cosas en una camara en quantia de 40 ducados.

200 quintales de carbon de encina.

100 cargas de carbon de fragua.

Ay 10.000 clavos de a 2 palmos y palmo y medio y un palmo e medio palmo.

200 cargas de lena del campo sin otras maderas viejas quebradas que se recoge de lo de la obra.

\section{DOCUMENTO 5}

Carta de Fernando el Católico al duque de Alba. Gerona 11 de Octubre de 1503.

(ADA. C-3-87).

Duque primo vi vuestra letra fecha ayer martes a medio dia y el memorial que con ellas embiastes a este vizcayno que vino deveys dar y tratar muy bien y darle esperanza de merced porque al cabo de la jornada si a nuestro señor plugiere y al que lo embia ofrecedle buena merced y trabaiad que de continuo vaya y venga assi secretamente y dezidle que mire bien a donde estan las estancias de las lobardas si estan a media cana o abaxo ygual con la cana o al borde della y si tira a las defensas baxas o a lo alto o al medio de la cerca y que mire bien que es lo que esta derribado de Salsas y de donde tiran los de dentro, digo de que partes, y que tanta gente es la que vino en el armada de mar para lo de tierra que a las vezes de mil faze cinco mil y si es gente de Saboya yo creo que vale poco, y que navios vienen en el armada y como armados y a donde se ponen si paran en la costa y donde o a donde va, y esto mismo trabaiad vos de saber por donde vieredes que se pueda saber y avisadme luego de todo lo que supieredes yo he despachado correos bolantes para que nuestra armada de mar que estava ya fecha en Malaga para venir a esta costa venga luego sin detenimiento si quando mi carta llegare no fuere partida y asimismo mando tomar todos los navios destas costas para la dha armada porque tengamos ahy dios mediante buena armada de mar y muy presto espero que sera asi mediante nro señor han me dicho que se podera fazer muy presto con hasta cc mil un baluarte en Por Vendres para defender que ninguna armada contraria se pueda poner en el y para nra armada quando fiziere mal tiempo pueda estar alli segura fazer lo luego ver al comendador San Martin para que si asi es se haga luego.

Y pareceme que segund lo que dize el memorial que embiastes que aprietan a Salsas que si no se faze alguna cosa con que se favorezcan los de dentro y teman mas lo de fuera que lo apretaran mas y se porna en peliegor y que en tan grande negocio pues ya teneys ahy tanta gente si no se acometiere alguna cosa de afrenta y ahun de algun peligro con su estancia que los de Salsas enflaquecerian y esto digo porque me parece que la estancia que los franceses tienen entre Perpinan y Salsas contra la puerta de Salsas que se podria llenar una noche acometiendo se rezio y concertadamente y pareceme que se deve provar, desta manera que escojays mil hombres a pie lo meiores que os pareciere en que haya vallesteros y algunos espingarderos ahunque estos poco aprovecha de noche y que se apeen algunos escuderos armados ligeramente de manera que todos mil hombres sean gente bien osada y suelta y que estos den en la estancia muy rezio con el ayuda de nro señor y que tengays afuera buen cuerpo de gente de pie y de cavallo para recogerlos y si dios les diere gracia y esfuerzo para que lleven aquella estancia podran estar las lobardas de los franceses en la cava para meterlos de alli dentro de Salsas y quando otro provecho no se alcançase de dar en la dicha estancia sino trabaiar en aquella rebuelta de meter un hombre en Salsas yo lo querria mucho para diga a don Sancho y a los que alli estan como ya la gente es venyda y que presto en nombre de nro señor de aqui para socorrer los con su ayuda y que presto salieran de aquella necesidad con muy crecida honra plaziendo a nro señor y sepan que tambien fazemos venir a esta costa gran armada de mar porque no la esperare para socrrerlos que el socorro luego por dios mediante y que pues fasta aqui lo han fecho como buenos cavalleros que asi lo hayan este poco de tiempo que queda fasta que sean socorridos y avise a don Sancho de lo de los cc que 
dizen que se querian salvar para que en todo mire y provea y escuse que los de la fortaleza no fablen con los franceses y digale que mire que las señales que fazen no son de los del memorial que el dio por esto que mire en fazer las conformes al memorial y quando se huviere de dar en la dicha estancia ved si sera bien fazer rebato con pocos peones y con una trompeta a la parte de la Sierra por desatinar a los del real y proveedle todo con el tiento y esfuerzo que se que lo sabeys fazer.

Agora es venido a mi Miguel Cardona que dize que Mosen de Bonaval que esta en este real le ha enbiado muchas veces a rogar que le fablen el y Martin de Salzedo que no los quiere sino sobre cosas que cumplen a abos los Reys conviene saber a nos y el rey de Francia y podria ser que los quiere especialmente a Cardona para otros fines y tambien podria ser tiento para ver si estamos en querer qualquiera paz para esforzar con ello su gente y parecer les que tal demostracion de nra parte seria mostrar que tenemos flaqueza no la haviendo a dios gracias y considerando esto pareciame inconveniente que estos dos fablasen con el de Bonaval porque nunca se deve cerrar por nra parte la puerta al espiritu santo y podria salir dello algun fruto pareceme que no por inconveniente que Cardona y Martin de Salzedo sepan que quiere el de Bonaval pero no deveys dar lugar que vayan al real de los franceses sino que el de Bonaval venga a algun lugar en el campo entre Salsas y Ribasaltas para que alli fable y de palabra lo podeys vos asegurar para ello sin dar nada por escrito que creo yo que el traera lo del seguro a Cardona si el ge lo embia a dezir y avisad secretamente a Martin de Salzedo que este siempre junto con Cardona y que delante del se fable lo que se hubiere de fablar no mostrando sospecha al Cardona y fagase secretamente sin que nadie lo sienta que agora va de aqui Cardona con carta nra para vos sobrello. De Girona a XI de octubre de quinientos y tres años.

Yo el Rey.

Por mandado del Rey. Miguel Ps. Dalmara.

\section{DOCUMENTO 6}

Perpiñán-Salsas octubre de 1503

(AHN. Universidades. General, leg 713.)

Las nuevas cosas que al presente ocurren y se han podido saber son las siguientes.

Parece que los franceses con necesidad que tenian de mantenimientos y temiendo que los nros ge los quitarian y creese tambien que no eran tantos que pudiesen resistir la gente de sus altezas delibraron se partir y asi lo fisyeron. La necesidad deviera ser grande porque diz que tenyan en tanto aprieto a Salsas que dentro de dos o tres dias la ganaran si pudieran esperar porque avian derribado los tiros dos torres cabecas y un paño que tenia encuentos para poner le fuego y asi diz que lo dijo uno al rey nro señor que diz que con mucho peligro salio de la fortaleza el dia antes que se fueron diziendo que si antes de dos dias no les socorria que los tomarian.

El duque dalva que tenia a legua y media su real como supo que los franceses se levantavan partio luego con su gente y aquel dia asento su real en la mesma Salsas donde ellos avian salido los franceses con todo su ejercito con toda su artilleria delante e la noche estoviera bien çerca de alli y en la sierra donde ellos estavan diz que estavan nuestros peones y por capitanes dellos el marques de Denia y don Fernando de Toledo con el dicho peonaje con quinientos ginetes y no se osaron travar con los franceses. Otro dia de mañana los franceses tomaron su camino ordenadamente y toda su artilleria delante y como el duque de Alva quedava atras el dicho don Fernando y el marques de Denia no curaron de seguirlos mucho. El Rey nuestro señor esa noche avia dormiado en Perpiñan aunque ya avia ydo y venido a Salsas y con todo eso madrugo para fallarse en la batalla y quando llego que era ya salido el sol aun no era partidos los mas en pos de los franceses y mucho avia que no avian cavalgado ... en este tiempo se avian adelantado los franceses pero todavia diz que yvan a vista de los nuestros en esto llego el obispo de Palencia y dijo que su alteza se devia bolver que harto avia fecho que estava ya dos leguas en tierra de Francia y para mas justificar su avla no eran razon de pasar delante diziendo que Dios nuestro señor lo recibiria a gran sobervia respondio su alteza padre echad nos vos la bendicion y bolveos que esto no es para vos ny cures dellos e mando Aguilar la gente en pos de los franceses aunque yvanle pos delantaronse algunos ginetes mancebos y mordibravan en las haldas de la gente francesa. 
Visto ellos esto dejaron atras unos xv o xx ombres de armas y algunros çuicos y que sola dicha que estos tomaron en medio aun Johan Lopez sobrino del camarero mayor y mataronle alli y al fijo del thesorero dieron algunas heridas e le cortaron e le cortaron dedos de la mano creese que esta para. Don $\mathrm{A}^{\circ}$ de Silva fijo del conde de Cifuentes diz que lo fizo bien y rompio su lança de gineta en un ombre de armas y despues peleo la espada y darga fasta que le mataron el cavallo y daronle xviii heridas y los çuiços despojaronle de armas y vestidos y dejaronle desnudo qual la madre lo pario aquien por muerto y asi le fallaron creese que no morira. Siguiendoles los nuestros los franceses fazian rostro quivera menester y viendo esto los grandes que con el rey nro señor yvan parescioles que no era razon de seguir mas aquella gente que yva muy determinada y ordenada especialmente porque nros peones no avian comido aquel dia y algunos otros asaz con la mas de la gente se bolvya que no los podian tener y asi acordaron con su Alteza de se bolver de que peso a muchos porque diz que si aquel dia los siguieran y se fiziera como se devia de fazer aquel dia se acabara la guerra con Francia. Tachan mucho en esto el descuido o negligencia de nra gente que diz que si dos horas antes salieran los despacharan del todo. Por ventura fue mas dado aquello ovio el duque que no convenia pensando ser mucha mas gente la de los enemigos aunque diz que no aiva mas de xv mil combatientes utiles en el real de los franceses artilleros y acadoneros y otra gente alla avia asaz.

En el real diz que no dejaron sino algunos maderos de tiendas e algunas vigas aunque pocas de las del parque que todo lo otro diz que quemaron e muchos toneles de botas vazias algunos diz que dezian que avian visto coraças quemadas pero el que escribio esto diz no avia visto tal cosa. Ciertamente diz que los franceses mostraron gran coraçon en su salida y bien todo lo fizieron como buenos guerreros pero si los nros no durmieran tanto ... diz que los francese tienen sentado su real aquende Narbona una o dos leguas.

\section{BIBLIOGRAFÍA}

ARANTEguI, J. (1887): Apuntes históricos sobre la artillería española en los siglos XIV y XV. Madrid.

CAAmaÑo, J.M. (1959): «Datos artísticos recogidos de los viajes de Antonio Lalaing». Boletín del Seminario de Arte y Arqueología. Valladolid.

Coвos, F. (1994): Fichas del catálogo: La paz y la guerra en la época del tratado de Tordesillas. Burgos.

Coвos, F. (2000): «Artillerie et fortification ibérique de transition aux environs de 1500». Actas del Simposio internacional sobre Castelos: Mil anos de forticaçoes ña península Ibérica e no Magreb (500-1500). Palmela.

Cobos, F. y De CASTRO, J.J. (1998a): Castilla y León. Castillos y fortalezas. León.

Cobos, F. y De CASTRo, J.J. (1998b): «Salsas y la fortificación de transición española». En Castillos de España, no 110-111.

Cobos, F. y De CASTRO, J.J. (2000a): «Edición anotada y comentada de la Apología del Comendador Escrivá». Luis Escrivá su Apología y la fortificación Imperial. Valencia.

Cobos, F. y De CAstro, J.J. (2000b): «Diseño y desarrollo técnico de las fortificaciones de transición españolas». La fortificación del Imperio de Carlos V. Madrid.

Cobos, F. y De Castro, J.J. (2000c): El castillo de Ponferrada. (Cat. expo.) (En prensa).

PorTo. (1982): A Artilharia em Portugal. (Cat. expo.) Porto.

Silva, I. (1996): Pinhel falcao. Pinhel.

FERnANdo Cobos Guerra - José JAVIER de CASTRo FERnÁNDEZ

C/ García Morato, 16, 4 I - 47007 Valladolid 